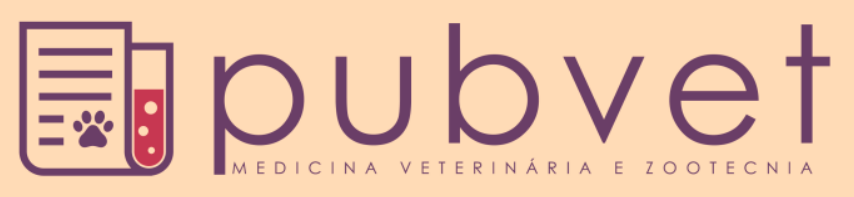

https://doi.org/10.22256/pubvet.v12n1a2.1-11

\title{
Touros de rodeio e seu bem-estar
}

\author{
Matheus Hernandes Leira ${ }^{1}$, Paula Gonçalves Santiago Pereira de Oliveira $^{2}{ }^{\bullet}$, Lucas \\ Silva Reghim ${ }^{2,3}$, Ana Paula da Silva², Daniel Tavares Caixeta², Jackson Patrocínio², \\ Milena Souza ${ }^{2}$, Daniela Ribeiro Cazelato Amorim ${ }^{2} \bullet$ \\ ${ }^{I}$ Médico Veterinário, Professor e Pesquisador, Universidade Federal de Lavras - Brasil. \\ ${ }^{2}$ Discente do Curso de Medicina Veterinária, Centro Universitário do sul de Minas, Varginha-MG-Brasil. \\ ${ }^{3}$ Bolsista de Iniciação Cientifica, Centro Universitário do sul de Minas, Varginha-MG-Brasil. \\ *Autor para correspondência, E-mail: matheushernandes@uol.com.br
}

\begin{abstract}
RESUMO. Temos por objetivo estimular a reflexão das pessoas, quanto ao exercício da atividade de rodeio e o tratamento recebido pelos touros, sempre respeitando seu bemestar, junto com o ordenamento jurídico brasileiro que prevê as leis sobre esta prática. Sabe-se da polêmica estabelecida no território nacional acerca da autorização por parte dos municípios, para a realização das festas tidas como "Festa do Peão de Boiadeiro", como são chamadas as festas de rodeio em várias regiões do país e para que esta polêmica finalize temos agora a PEC 304 que vem provar que os animais envolvidos nos rodeios são muito bem tratados.
\end{abstract}

Palavras chave: Bem-estar animal, rodeio, festa do peão

\section{Rodeo bulls and their welfare}

ABSTRACT. We aim to stimulate the reflection of the people, regarding the exercise of the rodeo activity and the treatment received by the Bulls, always respecting their wellbeing, together with the Brazilian legal system that provides the laws on this practice. One knows of the controversy established in the national territory about the authorization by the municipalities, for the accomplishment of the celebrations celebrated like "Peão of Boiadeiro", as the rodeo parties are called in several regions of the country and for this controversy to finalize We now have PEC 304 that proves that the animals involved in the rodeos are very well treated.

Keywords: Animal welfare, rodeo, cowboy party

\section{Toros de rodeo y su bienestar}

RESUMEN. Tenemos por objetivo estimular la reflexión de las personas, en cuanto al ejercicio de la actividad de rodeo y el tratamiento recibido por los toros, siempre respetando su bienestar, junto con el ordenamiento jurídico brasileño que prevé las leyes sobre esta práctica. Se sabe de la polémica establecida en el territorio nacional acerca de la autorización por parte de los municipios, para la realización de las fiestas tomadas como "Fiesta del Peón de Boiadeiro", como se llaman las fiestas de rodeo en varias regiones del país y para que esta polémica finalice ahora tenemos la PEC 304 que viene a probar que los animales involucrados en los rodeos son muy bien tratados.

Palabras clave: Bienestar animal, rodeo, fiesta del peón 


\section{Introdução}

Os rodeios são uma parceria entre o homem e o animal, um esporte radical que vem crescendo muito, e para que isso continue e dê certo existe várias pessoas envolvidas tanto para a realização da festa em um todo, quanto para o bem-estar animal, pois se eles não estiverem bem preparados e tratados o espetáculo não acontece (Leira et al, 2017). Os animais mais disputados pelas companhias têm sêmens comercializados com alto valor no mercado, e o aumento de $30 \%$ das competições no Brasil, previsto pela LNR (Liga Nacional de Rodeio), pode valorizar ainda mais o custo da genética do campeão.

No Brasil, estão sendo adotadas as técnicas de melhoramento genético para gerar verdadeiros atletas. A palheta de sêmen de touros campeões pode chegar a $\mathrm{R} \$ 10$ mil. Em torno deste valor estão implícitos os lucros acerca da linhagem e a publicidade do nome que o animal carrega (Nogueira, 2016).

Os animais de rodeio recebem tratamento especial, eles precisam ser bem cuidados e nutridos, para que seu desempenho não fique prejudicado. Duas vezes por dia recebem sua alimentação que é basicamente constituída de ração e volumosos (Busquilha, 2016). Dentre os alimentos dos touros podemos citar: silagem de milho, ração especial e balanceada, concentrado de milho, sorgo, feno de alfafa além de polpa cítrica e melaço de cana de açúcar, tudo sempre na dose certa e nas quantidades suficientes para manter a forma ideal para touros de rodeio. Com excesso de peso ou abaixo eles não alcançam os resultados que são necessários na arena, os touros brasileiros estão sendo referencia mundial, graças a sua alimentação controlada (Busquilha, 2016).

O transporte é em veículos apropriados e com todos os cuidados para que eles não se machuquem como, por exemplo, nas gaiolas os parafusos têm suas formas arredondadas, o assoalho tem que ser de borracha com palha de arroz ou serragem de madeira para não danificar os cascos dos animas. Vários outros cuidados para garantir a integridade física do animal (Busquilha, 2016). Geralmente viajam a noite por ser um clima mais fresco, assim os touros ficam menos estressados (ABTR, 2015).

Sempre monitorados desde sua partida até a chegada ao destino final por médicos veterinários, profissionais de rodeio, juízes, fiscais e pelos proprietários. Isto é para garantir que chegarão bem tanto nas festas de rodeio quanto em seu retorno para sua habita, observando suas condições físicas, mentais, sanitárias bem como o cumprimento das normas disciplinares que impedem os maus tratos (ABTR, 2015).

\section{A escolha do touro bom de pulo}

A escolha é feita pela genética e aptidão, se faz por volta dos 1,5 anos de idade. Como não são todos animais que possuem aptidão ao pulo, o rebanho passa por teste de aptidão, podendo ser utilizado o Dummy (robô cowboy) ou não. Aproximadamente $4 \%$ dos animais testados são selecionados. A partir daí uma média de dois touros são considerados bons de pulo (Busquilha, 2017). Os animais apartados do rebanho, começam a ter um manejo mais frequente para ir se condicionando, sendo então realizado acondicionamento ao manejo de curral, condução em corredores, condicionamento de brete com a corda de montaria e cinta de flanco, saída do brete para pulo com Dummy e retorno da arena. Este treinamento é realizado ao máximo de um episódio semanal, sendo o animal evoluído a fase seguinte somente após apresentar total condicionamento e sempre respeitando o que o Touro quer, sem força-lo a nada, e sempre devagar para não afetar sua forma física. Neste momento que inicia a montaria real, ou seja, com um peão (competidor) sobre seu dorso. Os animais passam então por nova seleção pela avaliação de seu pulo dentro dos cinco parâmetros de julgamento que são: salto, coice, grau de dificuldade, intensidade e giro, sendo então descartados os animais que não apresentarem pulos atendendo os quesitos.

Os touros além de pular em torno de 13 vezes em oito segundos, giram bastante e às vezes invertem o giro dificultando o equilíbrio $\mathrm{O}$ touro de pulo parte para sua apresentação de forma profissional por volta dos quatro anos de idade.

\section{Genética}

A seleção do touro bom de pulo também sofre influência da genética. $\mathrm{O}$ melhor touro para rodeio é o oriundo do cruzamento das raças Nelore e Marchigiana, tendo em vista que o Nelore é muito violento, ágil, enquanto o Marchigiana se impõe pelo tamanho. Juntando as duas raças dá um animal ágil, bravo e de bom tamanho (Leira et al, 2017). Não existe no Brasil um cruzamento específico de raças, mas basicamente os animais são provenientes do cruzamento de taurinos com 
zebuínos, onde sabemos estatisticamente que algumas raças taurinas possuem maior propensão ao pulo (Angus, Simental, Charolês e Marchigiana). Desta forma, animais dessas raças são cruzados com animais da raça zebuína, sobretudo, a raça Nelore para melhorar o desempenho destes animais nos rodeios.

Angus: Os rebanhos primitivos apresentavam predominantemente uma mesma cor, a preta. Mas, hoje em dia existem duas cores que diferenciam a raça. Ela pode ser Black (preto) ou Red (vermelho), alguns criadores consideram que o gado de cor vermelha apresenta maior resistência ao calor. Os machos desta da raça Angus são férteis e ganham peso com facilidade. Outra vantagem é que mesmo diante das dificuldades comuns enfrentadas pelas raças bovinas de origem europeia diante do clima tropical, ele apresenta rusticidade, o que favorece a adaptabilidade do rebanho nas diversas condições ambientais espalhadas pelo território brasileiro (Souza et al., 1995). Diante dessas e outras qualidades é que existem cruzamentos para Touros de rodeio a raça Angus.

Nelore: conhecido na Índia Oriental como Ongole, chegou ao Brasil no século XIV. A raça adaptou-se bem ao clima $\mathrm{e}$ às pastagens brasileiras. Naquela época, já eram realizadas experiências de cruzamentos entre raças de Zebu. (Santiago, 1985). O Nelore é um animal rústico, bravo, fértil, prolífero, longa vida reprodutiva e resistente às doenças comuns.

Marchigiana: Inicialmente, foi criada em regiões de climas extremos, com verões quentes e secos e invernos úmidos e frios, nas montanhas com pastos de qualidade inferior. Mesmo nestas condições desfavoráveis, a raça desenvolveu-se muito bem. No ano de 1965, um italiano que se tornou brasileiro, trouxe ao Brasil doses de sêmen de um touro Marchigiana famoso na Itália, realizando inseminações na cidade de Uruguaiana-RS, obtendo êxito. Posteriormente, este italiano distribuiu o sêmen recebido, entre vários criadores gaúchos. Adaptou-se muito bem ao Brasil, considerando-se seu local de origem. Esta é uma raça de significativa rusticidade e resistência às radiações solares e aos ectoparasitas (CNPC, 2008). Na busca de animais mais precoces, a raça passou por uma evolução nos últimos cinco anos. Houve uma sensível diminuição na altura dos animais com incremento na profundidade torácica, comprimento e musculosidade. Estudos indicam que esta raça possui boa capacidade de dissipar o calor adquirido do sol, sendo, portanto, bastante resistente e tolerante as condições do Brasil (Titto et al, 1998)

Simental: tem origem na Suíça, na montanhosa região do vale do rio Simen, de onde é derivado o seu nome. Os primeiros animais da raça Simental chegaram ao Brasil em 1904, importados pela Secretaria de Estado da Agricultura de São Paulo, com o objetivo de intensificar o fomento à Pecuária. A Associação Brasileira de Criadores da Raça Simental e Simentalsim - ABCRSS, bem como o "Gado Simental Brasileiro" são resultantes de um esforço realizado para resgatar os remanescentes das importações e seus cruzamentos selecionados na região Sudeste do Brasil. Os machos demonstram vigor no campo, rusticidade, velocidade de ganho de peso (ABCRSS - Associação Brasileira de Criadores das raças Simental e Simentalsim, 2015). Esta raça está em primeiro lugar entre as raças europeias, na produção de sêmen congelado, coleta e transferência de embriões, com opção para cruzamento industrial tem ótima aptidão genética (Nunes Carvalho, 1998).

\section{Treinamentos com o touro de rodeio}

Os touros são treinados como verdadeiros atletas. Do trote na fazenda à natação, os animais realizam exercícios musculares e recebem uma alimentação diferenciada. Os trotes na fazenda servem para fortalecer os músculos, o próprio relevo oferecido naturalmente pelas propriedades ajuda no condicionamento físico do animal e muito de seu condicionamento físico está ligado à sua genética (Busquilha, 2016).

Os touros comem em torno de $30 \mathrm{~kg}$ de silagem de milho, além de uma ração especial para touros atletas, com proteína e energia. Por causa dessa condição atlética que a alimentação é reforçada e balanceada com suplementos minerais e silagem de milho, duas vezes por dia combinação que dá mais energia e cria músculos no animal. A ração tradicional forma aquela gordura própria para o abate não para a condição física do animal atleta.

O treino começa cedo, quando eles têm 1,5 anos, são testados para ver se são bons puladores ou não. Essa característica independe da agressividade do animal. Quando o proprietário do animal verifica que ele é saltador, o separa do restante do rebanho e começa a treiná-lo junto dos outros animais usados em rodeios. Além de 
receber uma alimentação mais balanceada, ele é levado para represas ou lagos para nadar, praticar natação relaxa a musculatura e para corredores forrados de areia para correr. O objetivo dos exercícios é aumentar seu fôlego e sua resistência física. Quando o animal chega aos 4 anos, passa a frequentar os rodeios.

Nos rodeios primeiro eles são adaptados, antes de começar a participar das provas. Essa adaptação se trata de soltar o animal para passear pelas arenas e se acostumar com os barulhos, passadas nos bretes e outros animais. Somente depois de alguns passeios é que eles são colocados para participar do rodeio. Nunca é colocado para pular um animal que não foi aprovado em todo o período de treinamento, para que não haja estresse e desgaste por parte do animal (Busquilha, 2016). Os exercícios ficam restritos às fazendas onde os touros são treinados. Quando chegam ao palco do rodeio, eles desfrutam de sombra, água e comida apenas. Sua vida é regrada. É verdade, mas sem qualquer sofrimento. E levando em consideração os 8 segundos que eles ficam na arena eles trabalha menos de cinco minutos por ano em dias alternados, nunca em dias seguidos, isso ao longo de 25 rodeios disputados por todo o País. Ao contrário do que a maioria das pessoas pensam, os animais de competição têm um tratamento de primeira qualidade, com veterinários sempre à disposição e tudo mais que um atleta de ponta precisa. Assim o investimento se justifica. Sem a preparação adequada, os touros poderiam engordar e baixar consideravelmente seu rendimento (Vital, 2016).

\section{Alimentação}

Como estamos vendo a alimentação é de fundamental importância na vida dos touros de rodeio e o touro brasileiro é uma referência de desempenho nas principais competições de montaria pelo mundo. Mas por trás de pulos altos e grandes atuações nas arenas as boiadas são submetidas a um manejo alimentar rigoroso (Farias, 2015). Os animais são recolhidos de manhã onde recebem $30 \mathrm{~kg}$ de silagem de milho, além disso, tem a ração que é oferecida em torno de $6 \mathrm{~kg}$ por dia. O alimento é balanceado e especifico para animais atletas que necessitam de um nível de energia maior. Também consomem outro concentrado preparado à base de milho e aveia que ajuda na manutenção da pelagem e um suplemento de aminoácidos que dá energia aos touros (Farias, 2015). Misturado à ração feita de soja, trigo e milho e enriquecida com aminoácidos, vem também o isotônico que é composto de cálcio, sódio, potássio e outros sais minerais. O produto é dado aos animais logo após longas viagens. No dia seguinte ao rodeio, esse isotônico é usado porque assim como humanos, os touros têm um estresse fisiológico após o esforço e isso faz com que eles percam sais minerais por isso acontece essa reposição. Segundo profissionais do rodeio, um touro de pulo tem uma vida saudável. O consumo médio de alimento é sempre atendido, como por exemplo, $30 \mathrm{~kg}$ de silagem por animal pela manhã e permanência no pasto para ingestão de forragem e descanso. As informações são de que os animais recebem água a vontade, sal no cocho, e também ração balanceada para manter sua condição física para o esporte (Pereira \& Pierre, 2013).

Fora da temporada de rodeios, ou seja, todos os animais também recebem acompanhamento diário de veterinários, atividade física como trotear em uma pista de areia para desenvolvimento de suas musculaturas. Neste período os animais continuam recebendo dietas balanceadas com rações e volumoso para sempre manterem a condição atlética (Pereira \& Pierre, 2013). Além disso, touro acima do peso deixa de ser bom negócio. Podemos comparar os cuidados com o bovino à preparação de um jogador de futebol "Se ele estiver com uns quilos a mais, compromete seu desempenho, sua agilidade. $\mathrm{O}$ mesmo vale para os touros". Sem uma alimentação regrada, o boi poderia engordar 150 quilos, por exemplo, o que seria prejudicial para sua saúde inclusive.

Em uma boiada de 55 animais, por exemplo, são gastos 600 toneladas de silo por ano e 250 sacos de ração a cada 90 dias, que gera um custo em torno de $\mathrm{R} \$ 250,00$ por mês por animal (Busquilha, 2016). O investimento é alto, o custo pode chegar em uma boiada de 55 animais de $\mathrm{R} \$$ 5 a R \$ 7 mil apenas com alimentação mensal. Um animal desses chega a valer nos Estados Unidos, US\$ 150 mil, onde o esporte movimenta milhões de dólares. No Brasil, já atinge os R $\$ 50$ mil e o aluguel de cada bovino gira em torno de $\mathrm{R} \$ 600$ por fim de semana. Com tanto dinheiro em jogo, seria insano maltratar um touro de rodeio e acabar por perder ou não conseguir retorno de todo investimento.

Ração balanceada, sombra e água fresca, trabalho só de vez em quando: duas montarias por semana (ou menos). Assim é a vida de um touro de rodeio, muito melhor do que se pensa. "O exercício deles é descanso", afirma o tropeiro 
Chiquinho Nucci, proprietário da Cia de Rodeio Califórnia, em Taquaritinga (SP).

\section{Legislação federal sobre o bem-estar do animal e a segurança do competidor}

A prática esportiva de rodeio em touros no Brasil tem sido muito discutida por motivo de preocupação com o bem-estar dos animais, por isso, atualmente tem sido iniciado estudos de comportamento de animais que participam dessa modalidade esportiva, para conhecer o melhor manejo a ser empregado nas rotinas do rodeio (Pereira \& Pierre, 2013). Com isso foram criadas leis que e normatizam e regulamentam o rodeio, regulando a forma como devem ser organizados tais eventos esportivos e culturais (Leira et al., 2017).

Em 30 de Maio de 2017, foi a aprovação da PEC 304 que é uma Proposta de Emenda à Constituição. Acrescenta $\S 7^{\circ}$ ao art. 225 da Constituição Federal para determinar que práticas desportivas que utilizem animais não são consideradas cruéis, nas condições que especifica (BRASIL, 2017).

A PEC 304/17 altera a Constituição Federal para estabelecer que não são consideradas cruéis as práticas desportivas que utilizem animais, desde que as atividades sejam registradas como bem de natureza imaterial integrante do patrimônio cultural brasileiro e garantam o bemestar de cavalos e bois. A medida acaba com os entraves jurídicos para a realização de tais provas (BRASIL, 2017).

A Lei Federal no 10.519 de 2002 dispõe sobre a promoção e a fiscalização da defesa sanitário animal quando da realização de rodeio e dá outras providências. Esta lei estipula normas de como se organizar um evento de rodeio, esta lei foi criada para garantir a realização dos rodeios de forma segura, instituindo regras claras quanto à fiscalização e defesa dos animais (BRASIL, 2002).

A lei federal 10.220 foi finalmente criada em 11 de abril de 2001 e conseguiu de fato dar um pouco mais de respaldo ao trabalho dos atletas de rodeio e a realização desse tipo de evento e posteriormente em 2002 veio a ser melhorado com a criação de outra lei federal a 10.519 de 17 de julho de 2002 que instituiu regras para promoção e fiscalização da defesa sanitária animal quando da realização de eventos de rodeio (Leira et al., 2017).
De acordo com art. $4 .^{\circ}$ da Lei N. ${ }^{\circ} 135$, de 26 de agosto de 2001 (BRASIL, 2002) - Caberá à entidade promotora do rodeio, a suas expensas, prover:

I - A fiscalização relativa ao transporte dos animais quando da chegada dos mesmos até o local do evento, que deverá ser realizado em caminhões próprios para essa finalidade, que lhes ofereçam conforto, não se permitindo superlotação;

II - A fiscalização no sentido de que a chegada dos animais seja realizada com antecedência mínima de 6 horas até o município, devendo esses ser colocados em áreas de descanso convenientemente preparadas;

III - Os embarcadouros de recebimento dos animais deverão ser construídos com largura e altura adequadas, evitando-se colisões e hematomas;

IV - A infraestrutura completa para atendimento médico, com ambulância de plantão e equipe de primeiros socorros, com presença obrigatória de médico clínico-geral;

V - Médico veterinário habilitado, responsável pela garantia da boa condição física e sanitária dos animais e pelo cumprimento das normas disciplinadoras, impedindo maus tratos e injúrias de qualquer ordem;

VI - A arena das competições e bretes cercados com material resistente, altura mínima de dois metros e com piso de areia ou outro material acolchoado, próprio para o amortecimento do impacto de eventual queda do peão de boiadeiro, do competidor ou do animal;

VII - A alimentação e água potável para os animais, seguindo a orientação do médico veterinário habilitado, durante toda a permanência dos mesmos no local, inclusive após o evento;

VIII - A remoção de todos os animais após a realização das provas, sendo vedada a permanência nos currais que antecedem os bretes das provas;

IX - O manejo e condução dos animais somente serão permitidos com a utilização do condutor elétrico pelo médico veterinário ou tratador por ele supervisionado, sendo vedado o uso de ferrões, paus ou borrachas para essas finalidades;

$X$ - Iluminação adequada em todos os locais utilizados pelos animais, conforme orientação do médico veterinário; 
XI - Nas provas com a utilização de touros deverá haver a atuação de no mínimo um laçador de pista e nas montarias em cavalos, nos diversos estilos, a participação de no mínimo dois madrinheiros, para maior segurança do atleta participante.

\section{Normativas da Associação Brasileira de Touros de Rodeio}

Junto com as leis tem também a ABTR (Associação Brasileira de Touros de Rodeio), que possui um Manual de Conduta para todos os associados que é o regulamento do bem-estar dos touros de pulo nos eventos.

Todas as propriedades dos Associados da ABTR são vistoriadas previamente e deverão ser condizente com um local que produz touros de alto desempenho no quesito índole de pulo. Os animais são alimentados com pastagens e volumosos de boa qualidade, ração balanceada, sal mineral e água de boa qualidade. Devem conter instalações, curral, tronco de contenção para procedimentos e área de treinamento (arena), para condicionamento dos touros ao manejo do rodeio (comportamento no brete e saída da arena), e livro zootécnico, para anotações de todos os procedimentos realizados, (ABTR, 2015).

Objetivos básicos do regulamento e bem-estar dos touros de pulo nos eventos de concentração

Assegurar local adequado para descanso (pasto), para conforto dos mesmos, com espaço suficiente e divisões, respeitando a liberdade comportamental dos touros, com estruturas de curral, embarcador e tronco para procedimentos, previamente, vistoriados e aprovados pela ABTR.

Assegurar a ausência de fome e sede, com alimentação à disposição; Assegurar a ausência de ferimentos e doenças, com instalações limpas, mantendo medicamentos e apetrechos técnicos, utensílios adequados; Assegurar no recinto do rodeio, que o Médico Veterinário habilitado, especializado em Animais Atletas, ao qual estará afeta a responsabilidade do acompanhamento das condições físicas e sanitárias dos animais durante todo evento; Assegurar que a instalação no recinto do evento seja adequada e apropriada ao numero de touros utilizados (ABTR, 2015).

Para consecução dos objetivos, os proprietários ou seus funcionários, os tratadores, os promotores de eventos, os administradores do evento, os competidores, os médicos veterinários, a equipe de manejo, ou seja, todos que tenham os animais a seu cargo devem:

Proceder a um manejo condizente com a espécie animal (touro);

Ter conhecimento e capacidade comprovada no manejo de animais;

Assegurar que estrutura e os equipamentos das instalações, os medicamentos, os apetrechos técnicos, sejam apropriados e adequados para salvaguardar o bem-estar e sanidade dos animais;

Transportar em veículos apropriados e preparados;

Zelar pelo bem-estar animal durante a realização do evento, coibindo qualquer conduta agressiva com aos touros.

A proteção e integridade física dos animais compreenderão todas as etapas, desde o transporte dos locais de origem ao destino, o ingresso, o recebimento, as acomodações, o trato, o manejo, a montaria e o egresso;

Em todas as etapas de preparação e apresentação dos animais, o bem-estar dos touros deve estar acima de todas as outras exigências;

O não comprimento das regras deste regulamento, que está amparada no Art. $7^{\circ}$ da lei Federal $\mathrm{n}^{\circ} 10.519$, as penalidades previstas em legislações especificas serão aplicadas.

Os proprietários ou seu representante, a promotora do evento ou administradores do evento, os veterinários, os juízes das provas, os competidores, os embretadores, e retornadores, laçadores, entre outros profissionais, devem possuir um alto grau de conhecimento das áreas de atuação e devem assegurar o bem-estar dos animais utilizados no evento (ABTR, 2015).

\section{Das responsabilidades dos tropeiros}

O tropeiro ou proprietário ou seu representante, deve zelar para bem-estar do animal, e estar presente em todas as etapas no evento.

Fornecer touros de índole de pulo treinados para função e de qualidade comprovada, saudáveis e com boa saúde, com chifres cerrados (na circunferência de medida de uma moeda de um real), acompanhado de todos os exames e atestados exigidos pelo órgão de defesa agropecuária de cada Estado;

Todos os animais inaptos ou com aparente debilidade, devem ser retirado da prova; 
Tratamento apropriado seja prontamente dado a qualquer ferimento, ou situações de debilidade, bem como a assistência veterinária se requisitada;

Utilizar sedém ou cordinha de lá, nos padrões técnicos legais (

Das responsabilidades da promotora de evento e administrador

A promotora e administrador do evento são os responsáveis pela condução do evento e devem garantir o cumprimento dos padrões ora regulamentados, e garantir que:

Somente pessoal qualificado e competente esteja manejando e tratando dos touros;

Fornecer veterinário habilitado, que examine todos os touros antes, durante e após o evento;

Áreas cercadas (arenas e currais) e pastos sejam inspecionados antes do início do evento e esteja de acordo com os padrões técnicos legais, infraestrutura que garanta a integridade física dos touros durante sua chegada, acomodação e alimentação;

Todos os equipamentos, utilizados (sedém, cordas, esporas), sejam inspecionados previamente, permitindo a percepção que o modo como são usados sobre o animal cumpram todos os aspectos dos padrões técnicos legais;

Os animais utilizados no evento estejam em conformidade aos padrões técnicos e legais;

Os animais que apresentarem ferimentos, problemas de visão, fraqueza, devidamente atestada pelo médico veterinário, seja retirado da competição (ABTR, 2015).

\section{Das responsabilidades dos veterinários}

O médico veterinário é responsável por examinar os touros na sua entrada no recinto, ao mesmo tempo, atestar a saúde dos touros para a prova e pelo cumprimento das normas disciplinadoras, impedindo maus tratos e injúrias de qualquer ordem. Assim como, lidar com as emergências durante todo evento (ABTR, 2015).

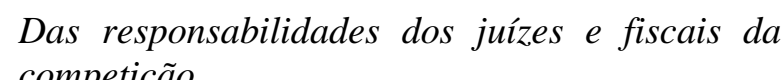
competição

São responsáveis de jugar o desempenho das apresentações e assegurar o bem-estar dos touros nas arenas e nos currais.
Vistoriar todos os touros; vetando os touros que não cumpram todos os aspectos dos padrões técnicos legais;

Vistoriar todos os equipamentos utilizados sobre o touro, vetando os que não cumpram todos os aspectos dos padrões técnicos;

Os fiscais de brete deverão ser aprovados ou indicados pela ABTR, devido seu grau de importância (ABTR, 2015).

\section{Das responsabilidades dos competidores}

Os competidores devem usar equipamentos aprovados e que cumpram os padrões técnicos e previamente vistoriados, devem respeitar e tratar o touro de forma humanitária (ABTR, 2015).

Das responsabilidades dos embretadores $e$ retornadores e laçador:

A equipe de manejo deve zelar pelo bem-estar dos touros, pelo período de sua responsabilidade, comunicando aos juízes do evento, qualquer irregularidade.

Apenas a equipe de manejo ou os proprietários ou seu representante, deverão realizar o manejo dos touros, em todas as etapas da prova;

Laçador deverá imobilizar o touro (laçar), se necessário para manter a integridade do competidor, caso contrário será utilizado touro madrinha;

O touro madrinha deverá ficar em um curral especifico e de fácil aceso.

Das Instalações nos Eventos e Anexos (ABTR, 2015).

Os eventos devem fornecer instalações adequadas e funcionais ao tipo de competição.

Arena deverá ser de tamanho razoável para o evento.

O piso da arena deverá ser firme, livre de buracos, pedras e outros obstáculos.

Arena deverá ser de areia fofa, com profundidade ideal de oito centímetros $(8 \mathrm{~cm})$, nivelada e compactada com água.

Arena deverá possuir cercas resistentes, de peso e aparência que desencoraje os touros de empurrar ou pular sobre elas, e sem saliências que possam machucar os animais, os competidores ou o público.

Os bretes deverão ser em número de seis, com três do lado direito e três do lado esquerdo, todos 
de tubos reforçados e com as seguintes dimensões: de "comprimento", dois metros e cinquenta centímetros $(2,50 \mathrm{~cm})$, até dois metros e sessenta centímetros $(2,60 \mathrm{~cm})$; de "altura", um metro e oitenta e cinco centímetros $(1,85 \mathrm{~cm})$, até um metro e noventa e cinco centímetros $(1,95 \mathrm{~cm})$; de "largura", de oitenta centímetros $(0,80 \mathrm{~cm})$, até noventa centímetros $(0,90 \mathrm{~cm})$; com a parte inferior das laterais fechadas no mínimo de setenta centímetros $(0,70 \mathrm{~cm})$.

A porteira de retorno da arena deverá abrir para os dois lados, facilitando o manejo, e medir no mínimo três metros (3,0 metros).

Deverá possuir um brete para retirada do sedém, após a montaria, facilitando manejo, nas mesmas dimensões já descritas.

Os currais de fundo deverão ser em quantidade proporcional a quantidade de touros no dia da prova; com montagem seguindo os padrões de manejo racional, evitando assim o stress no embreta mento e na apartação das boiadas.

Os embarcadouros de recebimento dos touros deverão ser construídos com largura e altura adequados, evitando lesões aos animais e garantir a segurança e facilitar a entrada e saída no veículo de transporte. Deve possuir altura máxima de um metro e trinta e cinco centímetros $(1,35 \mathrm{~cm})$, largura ideal de oitenta e cinco centímetros $(0,85$ $\mathrm{cm})$ e inclinação ideal de vinte graus.

Deverá haver o nivelamento do piso de saída do embarcadouro, para que o veículo transportador fique nivelado.

Os pastos ou piquetes deverão ser adequados ao número de touros e de boiadas no evento, com as devidas repartições de boiadas, com disponibilidade de água e volumoso de boa qualidade.

Os pastos ou piquetes (alojamento) deverão ser de fácil acesso, facilitando manobras dos veículos transportadores.

Todas as instalações deverão possuir iluminação suficiente e eficiente, para melhor manejo (ABTR, 2015).

\section{Diretrizes básicas para as provas}

Touros de pulo devem estar em forma e saudáveis para serem autorizados a competir.

As provas não devem prejudicar o bem-estar dos animais, implicando atenção especial às arenas, pisos, condições atmosféricas, currais, bretes, embarcadouros, alojamentos, segurança das instalações e saúde dos touros para viajar depois das competições.

Os Touros deveram estar presentes nos currais da prova, no máximo duas horas antes do início do evento; e ser retirados ao término do evento, no máximo em uma hora.

É vetada conduta antidesportiva ou de qualquer forma de má conduta que seja caracterizada irresponsável, ilegal, ofensiva, intimidadora, ameaçadora ou abusiva;

Caso proprietário ou seu representante detectar alguma irregularidade no momento da montaria deverá comunicar imediatamente ao Fiscal de Brete, para devidas providências;

Caso constatada irregularidade e não forem tomadas medidas imediatamente, o proprietário ou seu representante se reservara no direito de retirar o Touro em questão do evento, para preservar a integridade do animal, e lavrar Boletim de Ocorrência perante o órgão Oficial de Justiça.

Aplica-se a provisão deste artigo a todos envolvido no evento.

A direção do evento deverá expulsar ou desclassificar imediatamente indivíduos que apresentem condutas antidesportivas no recinto e enviar relatório ABTR.

\section{Equipamentos utilizados}

Sedém ou cordinha deverá ser de lã. No caso do sedém deverá possuir correias de comprimento no máximo um metro e setenta centímetros (170 $\mathrm{cm}$ ), de uma argola a ponta da correia e possuir dados do fabricante e aprovada pela ABTR.

As cordas dos competidores deverão ser de seda, achatadas ou torcidas (americana), e no mínimo de dezesseis milímetros $(16 \mathrm{~mm})$ de largura, com comprimento de hum metro e oitenta milímetros $(180 \mathrm{~mm})$ no mínimo, até dois metros e quinze milímetros $(215 \mathrm{~mm})$ no máximo, altura da alça no máximo nove centímetros $(9 \mathrm{~cm})$, com identificação do fabricante e aprovada pela ABTR

A espora deverá ser lisa e aprovada pela ABTR. (ABTR, 2015).

\section{As seguintes restrições deverão ser observadas}

$\mathrm{O}$ uso de equipamentos fora de padrão, tais como: sedém, corda, espora; 
Apresentar para a prova touros que esteja aparentemente apático, debilitado, de expressão contraída ou excessivamente cansada;

Os Touros não poderão permanecer nos currais da arena mais de uma hora após o evento;

O competidor que cometer abuso intencional com o touro será desclassificado;

Todo touro que estiver com sangramento causado por ação direta do competidor, durante a competição quanto do uso dos equipamentos (espora e corda), será desclassificado;

Touro que se apresentar com algum tipo de ferimento, o juiz deverá desclassificar o animal. (ABTR, 2015).

\section{Dos animais feridos nos locais de competição}

Os touros lesionados no local da prova deverão ser imediatamente isolados e transportados de forma segura ao local de procedimento, por equipe especializada; ficando a cargo do médico veterinário responsável do evento;

Se o touro apresentar lesões ou sofrimentos, não responder ao tratamento, e sessar todas as possibilidades e não puder ser deslocado sem lhe causar sofrimento adicional, poderá ser sacrificado, a cargo do médico veterinário responsável, seguindo os métodos humanitários, segundo a legislação especifica vigente.

Todas as medidas deste regulamento deverão ser integradas e em conjuntas.

A ABTR tem por compromisso, os bons tratos e bem-estar dos touros, a missão é atuar de forma profissional, fornecendo Touros de qualidade, saudáveis e diferenciados ao Pulo, garantindo que os contratantes possam oferecer uma estrutura digna de receber os atletas de Pulo sem que comprometam o bem-estar destes (ABTR, 2015).

\section{O papel do médico veterinário}

$\mathrm{Na}$ legislação, é atinente ao Médico Veterinário a Responsabilidade Técnica do evento, sendo a autoridade sanitária dentro do mesmo; sendo assim, o representante do Estado no evento. Fazer por cumprir as leis é sua função primordial e dentro desta estão suas atividades com relação à fiscalização zoosanitário, fiscalização de equipamentos utilizados nas modalidades esportivas e respeito ao bem-estar animal (ABTR, 2015).
Devido ao grande debate social sobre questões envolvendo o bem-estar animal no esporte com os mesmos, o médico veterinário tem assumido o papel de consultor técnico da área, onde sua função inicia desde o planejamento do recinto, sua montagem e execução das atividades.

Documentar e cadastrar o evento nos órgãos competentes, receber os animais e atestar sua saúde para o esporte em questão, estar de prontidão caso necessário (ABTR, 2015).

A princípio, todos os animais passam por exames sanitários e físicos por toda a vida inclusive antes de entrar nas arenas. Os animais chegam em média uma hora e meia antes do Rodeio nos bretes, e vão embora para seu lugar de descanso assim que terminam as montarias. Tudo isso é controlado e fiscalizado pelo médico Veterinário que tem a responsabilidade de executar um bom trabalho assegurando assim o bem-estar dos touros, bem como sua integridade física (Busquilha, 2016).

Os touros que não estiverem bem fisicamente são cortados antes de chegarem ao rodeio. Esta prática é feita por observação de sua condição e comportamento (Busquilha, 2016). Antes mesmo do embarque, e caso isso não ocorra o médico veterinário responsável pelo evento, tem a obrigação de não deixar que o animal com qualquer avaria que seja, participe da prova.

Antes dos animais chegarem ao recinto à equipe veterinária checa o ambiente em que os animais ficarão até a hora de começar as montarias, exemplo, isto é, os embarcadouros, querências e bretes entre outros.

Procedimentos feitos diariamente pelos proprietários visa o bem-estar dos touros. Eles são fechados e examinados para ver se tem algum ferimento, causado pelo atrito entre um touro e outro o que é muito comum. Da mesma forma, é feito um controle sanitário em todo o processo, a cada 90 dias é aplicado um remédio contra parasitas, fora isso somente medicamentos para curar ferimentos, tudo isso sob a orientação do Médico Veterinário (Busquilha, 2016).

\section{Equipamentos utilizados nas montarias}

Sedém - corda feita de lã ou com fíos do rabo do cavalo, amarrada na virilha do animal. É usado para estimular os pulos. Não machuca, apenas faz cócegas (Busquilha, 2016). É usado em todas as modalidades de montaria em cavalos e touros. Ele não aperta os testículos dos touros, pois é 
posicionado na virilha sem qualquer contato com esse órgão. Por outro lado, há um distanciamento ainda maior desse utensílio durante os saltos, evidenciando não haver ação mecânica do sedém sobre a bolsa escrotal dos animais, tal fato explica a não constatação de alterações ao exame andrológico, frequentes em animais com lesões testiculares, especialmente provocadas por ação mecânica ou nos submetidos ao estresse (Leira et $\underline{\text { al, 2017). }}$.

Espora - Instrumento utilizado pelos peões para obter um melhor desempenho do animal. É composta pelo cachorro, que preso a um arco suporta a roseta. Este acessório fica localizado na parte traseira das botas dos cowboys. Existem vários tipos, mas todas devem seguir uma padronização arredondada. Ela não machuca a pele dos animais, pois esta é de cinco a sete vezes mais espessa do que a pele humana. Outra questão é a de que as esporas permitidas seguem as especificações da Lei Federal, cujas pontas são arredondadas. Os competidores que violam essa regra recebem multa, suspensão e/ou desqualificação.

Corda Americana - Acessório que envolve o tórax do animal, onde o peão segura com a mão de apoio. Feita de náilon ou rami (fibra vegetal), é trançada manualmente e recebe breu para possibilitar maior aderência ao segurá-la com luva. Usado apenas na montaria em touros.

Polacos - Sinos amarrados junto com a corda americana que tem duas finalidades, servir de enfeite e ajudar a corda a se soltar do animal mais depressa, derrubando-a.

\section{Conclusão}

Os criadores de touro de rodeio têm a consciência de que se o animal for bem tratado, lhe trará o resultado esperado que são os pulos, em contrapartida os Touros nos demonstram isso com as apresentações nas arenas dando seu melhor, isso devido a ter suas 5 liberdades respeitadas dentro do que diz respeito ao bem-estar animal. Os animais de rodeio não sofrem nenhum tipo de agressão e maus tratos, devido a toda beleza, força, desempenho, agilidade e habilidade apresentadas. Outra consideração muito importante no que diz respeito ao médico veterinário que tem a obrigação de fiscalizar, cuidar, manter e exigir o bem-estar dos animais, antes, durante e após os eventos.
Ainda existe muito preconceito e falta de informação por partes de algumas pessoas leigas que desconhecem a forma com que os touros são tratados, e é com o intuito de acabar com esse paradigma, que deixa uma má impressão, e denigre o rodeio.

\section{Referências Bibliográficas}

ABCRSS - Associação Brasileira de Criadores das raças Simental e Simentalsim. 2015. Conheça a raça Simental http://simentalsimbrasil.org.br/raca-simental/, (Acessado: 28 maio, 2017).

ABTR - Associação Brasileira de Touros de Rodeio. 2015.

http://www.abtroficial.com/home, (Acessado: 5 de maio, 2017).

BRASIL. 2017. Legislação Federal. Art. 225, emenda constitucional $n^{o}$ 96. Práticas desportivas que utilizem animais não são consideradas cruéis, nas condições que especifica.

Busquilha, F. 2016. Companhia de Rodeio FBulls, http://fbulls.com.br/, (Acessado: 5 de maio, 2017).

CNPC. 2008. Marchigiana, Brazilian National Beff Cattle Concil. 1 pág.

Farias, S. 2017. Como criar um touro campeão, Jornal da Pecuária, http://www.canalrural.com.br/noticias/jornalda-pecuaria/como-criar-touro-campeao58810, (Acessado: 10 de Junho, 2017).

Júnior, C. ABTR - Associação Brasileira dos Criadores de Touros de Rodeio, 25 de janeiro de 2015 , http://www.vempraarena.com.br/p/abtrassociacao-brasileirade-touros-de.html, (Acessado: 20 de Abril, 2017).

Leira, M. H., Reghim, L. S., Peregrino, L. C., Honda, C. N., Félix, J. I. C, Silva, F., de Almeida, F. D. C. \& Cunha, L. T. 2017. A origem do rodeio no Brasil sua prática como esporte radical e o bem-estar dos animais de montaria. PUBVET: Publicações em Medicina Veterinaria e Zootecnia, 11, 207-312.

Nogueira, N. 2016. Touros de Rodeio: O preço da genética campeã conheça as raças mais usadas nas montarias. https://www.comprerural.com/touros-derodeio-o-preco-da-genetica-campea-conheca- 
as-racas-mais-usadas-nas-montarias/, (Acessado: 16 de Maio, 2017).

Nunes de Carvalho, F.A. 1998. A saga do Simental no Brasil, Midiograf, 424 págs.

Pereira, C. R. J. \& Pierre, R. A. 2013. Bem-Estar de Touros de Rodeio. Febovi, 4, 1-2.

Santiago, A. A. 1985. O Zebu na Índia, no Brasil e no Mundo. Instituto Campineiro de Ensino Agrícola, Campinas, 742 págs.

Souza, J. S. I., Peixoto, A. M. \& Toledo, F. F. 1995. Enciclopédia agrícola brasileira. Edusp, São Paulo, 508 págs.

Titto, E. A. L., Velloso, L., Zanetti, M. A., Cresta, A. \& Martins, J. H. 1998. Heat tolerance test in
Nelore and Marchigiana bulls. Portuguese Journal of Animal Science, 5, 67-70.

Vital, N. 2016. O touro que vive como atleta. Dinheiro rural, 37, 33-34.

\section{Article History:}

Received 25 August 2017

Accepted 5 October 2017

Available on line 8 November 2017

License information: This is an open-access article distributed under the terms of the Creative Commons Attribution License 4.0, which permits unrestricted use, distribution, and reproduction in any medium, provided the original work is properly cited. 